\title{
Introductory note
}

\author{
Jadwiga A. Jarzyna ${ }^{1} \cdot$ Michał Stefaniuk ${ }^{2}$
}

Published online: 13 November 2019

(c) Institute of Geophysics, Polish Academy of Sciences \& Polish Academy of Sciences 2019

AGH University of Science and Technology (AGH UST), Krakow, Poland, was established a 100 years ago, in 1919 year. Among many events dedicated to the anniversary celebration, there was also the scientific conference "Challenges in Applied Geology and Geophysics: 100th Anniversary of Applied Geology at AGH University of Science and Technology (CAGG2019)" held at the Faculty of Geology Geophysics and Environmental Protection, AGH UST on 10-13th September 2019 year. Conference was the platform of specialist idea exchange, talks about cooperation and just presentation of deliberations related to the Earth sciences problems and questions considered today, in the past and in the future.

Applied geology and applied geophysics were taught since the very beginning of the AGH existence. Graduates from the AGH University and especially from the Faculty of Geological Prospection, now Faculty of Geology Geophysics and Environmental Protection, and people cooperating with the AGH University staff prepared many presentations for the conference which built the review of the directions in which applied geology and applied geophysics develop and the background for the discussions about future.

The special issue of the Acta Geophysica journal entitled "New methods and methodologies in applied geophysics and geology - The 100th Anniversary of AGH University of Science and Technology, Krakow, Poland" includes the papers presented at the CAGG2019 Conference and is mostly dedicated to geophysical solutions in data acquisition, processing and interpretation and case studies.

Geophysics was present in Krakow since more than 50 years when in the academic year 1945/1946 at the Mining

Jadwiga A. Jarzyna

jarzyna@agh.edu.pl

1 Department of Geophysics, Faculty of Geology Geophysics and Environmental Protection, AGH University of Science and Technology, Kraków, Poland

2 Department of Fossil Fuels, Faculty of Geology Geophysics and Environmental Protection, AGH University of Science and Technology, Kraków, Poland
Academy (the first, historical name of the AGH UST), at the Geological Surveyor Faculty lectures on applied geophysics were assigned to prof. Edward Walery Janczewski (1887-1959), the Head of the Geological Geophysics Chair. The Chair of Mathematical Geophysics and Meteorology, the first in Poland and in Europe, was established in 1895 at the Jagiellonian University in Krakow for Maurycy Pius Rudzki (1862-1916).

At the very beginning, the Geological Geophysics Chair at the Mining Academy consisted of four departments: General Geophysics and Geoanalytics, Prospecting Magnetic and Gravity, Prospecting Seismic Methods and Prospecting Electric Methods. Research and education in the abovementioned branches are still realized and extended to new methods resulting from the technology development in the applied geophysics. To the relatively new groups of geophysical methods, with physical background well known but specialized for solving real geological and prospecting problems belong for instance magnetotelluric measurements and GPR investigations. Some new technologies were initiated at the AGH UST. Here, microgravity investigations developed by prof. Zbigniew Fajklewicz and mining geophysics developed by prof. Stanisław Małoszewski were included to the research and education profile. Petrophysics and well logging analysis developed by prof. Stanisław Plewa and prof. Adam Gawin at the Faculty of Geological Prospecting (next Geology Geophysics and Environmental Protection) were presented to the Polish students only at the AGH UST.

Applied geophysics closely cooperates with applied geology. The presence of applied geophysics besides geology of mineral deposits, petroleum geology and mining geology, mineralogy, petrography, geochemistry, hydrogeology, engineering geology, geoinformatics and environmental protection at the Faculty of Geology Geophysics and Environmental Protection, AGH UST, generates good conditions for cooperation and mutual motivation to obtain the best results in geological and environmental problems solutions. During the years, the new areas arose where applied geophysics turned to be effective and not expensive tool. Engineering and environmental geophysics built the platform 
where techniques and methodologies known and used in prospection were applied to solve quite new tasks. Renewable energy projects also used the knowledge of reservoir properties of rock formations well described from the seismic investigations in big scale, well logging in mezzo-scale and laboratory petrophysics in microscale.

Nowadays, geological recognition of complicated and difficult rock formations being the hydrocarbon and water reservoirs and objects for raw materials prospection like cuprum or lead ores, sulfur and even rare elements is a real challenge and applied geophysics armed with sophisticated methods of data acquisition and advanced processing methodologies is helpful and effective in cooperation with geologists.

The special issue presents the papers which illustrate the progress in applied geophysics in the last years, development of acquisition methodologies, processing systems and applying advanced computer techniques to data mining in geological interpretation combining results from all available sources. The papers were prepared by graduates from the AGH UST actually doing science in applied geophysics working at the university units, employed in companies and research institutes. Some of the papers are presented by staff members of the university faculties and departments which cooperate with the Faculty of Geology Geophysics and Environmental Protection, AGH UST, at the educational platform in Poland and also abroad. Graduates employed in the institutes of the Polish Academy of Sciences still keeping contact with colleagues from the AGH UST implementing the methods of general geophysics to applied geophysics problems also submitted their articles. Also, representatives of Oil and Gas Institute-National Research Institute in Krakow being the research institution closely cooperating with industry units are the authors of submissions. So, the centenarian Academy of Mining, next Academy of Mining and Metallurgy and now AGH University of Science and Technology in Krakow, Poland, is still the platform of knowledge exchange, place of creating new methodologies and developing novel applications of solutions elaborated abroad. The special issue comprises also the fruits of the education and specialist work on creating new concepts in applied geophysics initiated at the AGH UST.

Set of papers presented in the special issue of the Acta Geophysica journal reveals the vast spectrum of problems solved using methods and methodologies of applied geophysics. As first, we mentioned the results of aerogeophysical datasets used to enhance the success of the conventional geological mapping for obtaining a general geological view of the studied region. Airborne radiometric and magnetic datasets as results of the modern data acquisition technologies and the newest processing methods provided solutions in unrecognized lithologic zones. Similarly, 2D gravity-density inversion was realized for the modeling of the basin basement in the Banat area in Serbia. Another example, related to microgravity surveys, is concerned on the analysis of gravitational effects caused by the buildings, important in the gravity (microgravity) research carried out on urban areas.

Papers dealing with the seismic methods used for special geological structures determination and rock formation characterization illustrate great development of these technologies in the area of processing and interpretation. To acquire refined seismic targets, the use of more accurate and more precise methods of signal processing is crucial. Application of dip-guided filtering combined with beam-partitioned analysis and $\mathrm{Z}$ domain dip analysis for reprocessing $3 \mathrm{D}$ and 2D seismic data from the Carpathians region is important in case of the complex geology of mountains area, especially when the signal-to-noise ratio and general data quality is low. Bright spots can be caused by different reasons, such as even weak gas or water saturation, but also seismic interference known as tuning effect. It is crucial to differentiate between seismic anomalies and be able to verify them within the siliciclastic Miocene sediments of the Carpathian Foredeep. Application of AVO analysis and spectral decomposition turned to be effective solutions in that case. Optimal processing of the seismic profile 2D-3C located in the Carpathian Foredeep, Poland, which integrated seismic images of three-component 2D seismic line (2D-3C seismic) conducted to obtain stacks and prestack gathers with preserved amplitude relations confirmed existence of the hydrocarbon reservoir. Methods developed for seismology and seismic prospecting can be successfully applied in microseismics tasks. In the presented paper, peak-frequency method was used to estimate effective P-and S-wave quality factors $\left(Q_{\mathrm{P}}\right.$ and $Q_{\mathrm{S}}$ ) based on the recorded waveforms of microseismic events. Higher $Q_{\mathrm{S}}$ than $Q_{\mathrm{P}}$ values were consistent with attenuation coefficients of saturated reservoirs.

Application of geophysical methods in the engineering geology has important meaning from the landslide hazard evaluation point of view. Example from the landslide in the south of Poland presenting passive seismic interferometry (SI) and active multichannel analysis of surface waves (MASW) methods, both using surface waves, revealed good effectiveness in estimation S-wave velocity field. Landslides are complex phenomena, and one of the main factors influencing their stability are changes in water conditions. The combination of geophysical-Electrical Resistivity Tomography (ERT) and geotechnical-Cone Penetration Testing (CPTU) methods can provided reliable information on the geological structure and geotechnical parameters of the landslide. ERT method is frequently used to solve various geological problems. The method is intuitively simple because of its physical basis but with sophisticated interpretation provides unique data, especially in mountain areas so far been interpreted only on the basis of geological exposures. 
Models based on geoelectrical measurements allowed to characterize the structure of the rock mass, including the reach of the rainwater infiltration level and the depth of the weathering front. Combination of geophysical methods, for instance seismic refraction and ground penetrating radar (GPR) can contribute satisfactory results in the diagnosis of the geological structure and physical features of the mountain rocks despite difficult acquisition conditions associated with large differences in the depths of the mountain area, dense foliage, occurrence of rocky soil and very difficult accessibility of the place. Also, on the sea shore Vertical Electrical Soundings (VES) apparent resistivity data performed using a set of novel software for forward modeling with digital linear filtering allowed the simulation of theoretical VES responses for horizontally layered geological media with virtually unlimited number of layers. The pseudo-inversion component from the software applications was based on a random sampling of the parameters space of the geoelectrical models. Another application of ground conductivity meter and DC resistivity methods were used to precisely determine the thickness of the soil and impermeable clay as well as the depth of the gypsum basement in one of the Krakow settlements. High flat blocks for inhabitants are planned to be built in the area of the gypsum basement covered by the soil and impermeable clay beds with several meters of thickness. The flat blocks must be set on the textured gypsum layer. As the result of the rainfall and static pressure of the blocks, the water with $\mathrm{SO}_{4}{ }^{2-}$ increases up to the groundwater level. It becomes the great threat for the flat blocks in the zone of the building's foundations. Similar problem was solved using GPR and ERT surveys carried out on the sites in Poland where shallow karst forms were found in gypsum deposits. It was shown that non-invasive detection of karst forms as well as weathered and fractured bedrock which may threaten the stability of the surface and may cause damage to buildings, as well as overground and underground infrastructure can be successfully done by geophysical methods. Effectiveness of the transient electromagnetic method (TEM) was tested in the difficult geological ore deposit in Northern Vietnam based on the results of the modeling processes. The results enabled proper selection of the parameters as resistivity of ore bodies and host rocks, current power, geometry and frequency of transmitting system and level of noise indispensable for proper acquisition and interpretation of field data.

Ground penetrating radar is known as geophysical method useful in archeology. Example presented by international team from Albania and Italy showed that the exact location of the buried archaeological structures may be done using the different non-invasive geophysical techniques: magnetic prospecting survey, electromagnetic induction method (EMI) and ground penetrating radar. The main goal was to determine the exact shape and therefore the best excavation strategy for the buried archaeological structures. The excavations confirmed the results obtained during the magnetic surveying. GPR survey was carried out to refine the EMI interpretation and identify the sources of EMI anomalies at a smaller scale and at different depths. Effective, efficient and reliable interpretation of GPR field data obtained from the clandestine sites are also crucial in the forensic investigations. Analysis of the finite difference time domain numerical simulation of GPR measurement for locating burial sites was presented as helpful technique for interpretation of GPR anomalies. Advanced artificial intelligence technology was presented as a powerful technique to enhance geotechnical information from GPR measurements applied to river embankments to check their stability for flood prevention. Artificial neural networks (ANN) in the supervised and unsupervised variants turned to be useful to perform the automatic classification of weakened zones within the embankments.

Advanced statistical methods were also used for rocks classification on the basis of well logging and laboratory data. Great amount of well log data predestinates statistical methods. Cluster analysis, support vector machine and artificial neural network (ANN) - Kohonen algorithm were used, and results were compared and analyzed to obtain electrofacies in the unconventional hydrocarbon deposits. Detailed study on permeability estimation was also done using ANN.

Several papers were dedicated to parametrization of the pore space of tight rocks from Poland based on laboratory measurements and well logging. It is worth to underline that the newest laboratory techniques like computed X-ray tomography (CT) together with nuclear magnetic resonance spectroscopy (NMR), pulse- and pressure-decay permeability methods providing the information about the geometrical parameters of the pore space were successfully combined to obtain results in microscale. Detailed investigations of petrophysical parameters were performed for low-permeability reservoirs. Among others Flow Zone Index (FZI) calculations and heterogeneous rock analysis (HRA) were made for permeability prediction of tight sandstones. Concurrently, well logging interpretation methodology was proposed for carbonate formation fracture system determination. In petrophysical block of problems, an attempt to use the rock physics template concept in characterization of the organic shales was also presented. A cross-plot of $\mathrm{Vp} / \mathrm{Vs}$ ratio against acoustic impedance of $\mathrm{P}$ wave was proposed to estimate the fluid and mineral content of a reservoir. Well logging problems discussed in the special issue comprised also the theoretical solution concerned on an iterative inversion of dual induction tool logs from the thin-bedded sandy-shaly formations of the Carpathian Foredeep using a modified simulated annealing method. The problem of proper interpretation of anomalies observed in neutron logs 
in the thin-bedded Miocene formation was also undertaken on the basis of Monte Carlo simulations results.

In the introductory note, we pointed out the selected problems discussed in the published papers. The described solutions and presented case studies are only the small section of themes which applied geophysicists face all the days. The presented papers proved challenges in applied geophysics which are undertaken in the theory and practice by scientists and engineers to prepare precise answers on the basis of geophysical solutions to questions asked nowadays by geoscientists recognizing the more and more complicated rock formations. 